\title{
Implementasi Metode Fuzzy Tsukamoto Pada Pertimbangan Peningkatan Insentif Karyawan Perusahaan Cabang PT Pinus Merah Abadi
}

\author{
Arridha Zikra Syah ${ }^{1}$, Rizaldi ${ }^{2}$ \\ Program Studi Sistem Informasi , STMIK Royal Kisaran \\ Jl. Prof. M. Yamin 173 Kisaran, Sumatera Utara 21222 Telp : (0623) 41079 \\ E-Mail : azsyra@gmail.com ${ }^{1}$, rizaldipiliang.rp@gmail.com ${ }^{2}$
}

\begin{abstract}
PT Pinus Merah Abadi is a distributor company in Indonesia. They engaged in selling snacks such as snacks and wafers with Nabati brand. They expends incentives for their employees every month. The expending of incentive depends on pre-determined terms or targets each month with specified terms and targets and intense competition from other employees. However, in the calculation process of incentives is managed manually using the criteria by the Personnel General Affair. Then the data from the manual calculation are sent to the head office. Sometimes the results of the decision are too rigid. The research method used is descriptive qualitative. The results of the study show results that have the effect of incentives with all achievements between incentives towards employee achievement performance simultaneously. The amount of incentives depends on the ruled given. The income difference for each criterion for each employee will cause a difference in income.
\end{abstract}

Keyword: Fuzzy Tsukamoto, Considerations for Increased incentives

Abstrak-PT Pinus Merah Abadi adalah salah satu perusahaan distributor di Indonesia yang bergerak di bidang penjualan makanan ringan seperti snack dan wafer dengan brand Nabati. Perusahaan ini juga setiap bulannya mengeluarkan insentif bagi para karyawannya dengan syarat atau target yang telah ditentukan sebelumnya setiap bulannya dengan syarat dan target yang ditentukan serta persaingan yang ketat dari karyawan-karyawan lainnya. Namun pada prosesnya, perhitungan insentif dikelola secara manual menggunakan kriteria oleh Personalia General Affair yang kemudian data hasil perhitungan manual tersebut dikirim ke kantor pusat. Terkadang hasil keputusan tersebut terlalu kaku. Metode penelitan yang digunakan adalah deskriptif kualitatif. Hasil penelitian memperlihatkan hasil yang terdapat pengaruh insentif dengan semua capaian antara insentif terhadap kinerja pencapaian karyawan secara simultan. Besaran insentif bergantung pada ruled yang diberikan. Perbedaan pendapatan setiap kriteria pada setiap karyawan akan menyebabkan perbedaan pendapatan.

Kata Kunci: Fuzzy Tsukamoto, Pertimbangan Peningkatan insentif

\section{PENDAHULUAN}

Sistem Pendukung Keputusan berbasis Kecerdasan buatan sangat diminati oleh kalangan bisnis dan peneliti saat ini. Sistem informasi jenis ini dibutuhkan untuk Pendukung Keputusan oleh lini manajemen tingkat menengah ke atas sebagai rekomendasi alternatif yang lebih manusiawi. Salah satu metode yang digunakan oleh sistem jenis ini adalah metode Fuzzy. Metode ini sangat sarat dengan penalaran yang sesuai dengan konsep penalaran manusia. Pegawai adalah orang yang akan menjadi sumber daya utama yang sangat dituntut untuk memenuhi kepuasan konsumen, serta dituntut oleh perusahaan dalam pengoptimalan kinerja pada bidangnya masing-masing. Demi meningkatkan mutu karyawan yang potensial dan bermutu, biasanya perusahaan melakukan berbagai macam cara melalui berbagai proses dan ketentuan dari perusahaan agar mencapai tujuan perusahaan yang diinginkan. Salah satu cara yang digunakan memberikan motivasi kerja dalam bentuk peningkatan penghargaan berupa insentif. Insentif dan bonus juga termasuk salah satu suntikan semangat dan motivasi bagi para 
karyawan untuk bekerja dengan giat dan sungguh-sungguh, maka dari itu perusahaan juga harus sudah memikirkan seberapa besar bonus dan insentif yang diperuntukkan bagi para karyawan yang telah melaksanakan tugas nya dengan gigih demi tercapainya tujuan perusahaan[1]. PT. Pinus Merah Abadi adalah salah satu perusahaan distributor di Indonesia yang bergerak di bidang penjualan makanan ringan seperti snack dan wafer dengan brand Nabati. perusahaan ini adalah sebuah perusahaan Nasional yang mempunyai cabang diseluruh wilayah Indonesia untuk mendistribusikan barang dagangannya, perusahaan ini juga setiap bulannya mengeluarkan insentif bagi para karyawannya dengan syarat atau target yang telah ditentukan sebelumnya setiap tahunnya dengan syarat dan target yang ditentukan serta persaingan yang ketat dari karyawan-karyawan lainnya. Namun pada prosesnya, perhitungan peningkatan insentif dikelola secara manual oleh manajer. Kemudian manajer mempromosikan nama-nama karyawan yang layak berdasarkan perhitungan tersebut ke kantor pusat. Berdasarkan study pendahuluan yang dilakukan pada perusahaan tersebut menyangkut pemberian pormosi peningkatan insentif, B karyawan yang sebenarnya layak namun karena kurangnya poin dalam satu kriteria, karyawan tersebut tidak memperoleh promosi.

Untuk itu dibutuhkan satu buah sistem yang menggunakan nalar untuk mendukung keputusan peningkatan karyawan pada kantor cabang PT. Pinus Merah Abadi. Sehingga setiap karyawan yang diusulkan untuk memperoleh kenaikan insentif bisa dihitung sesuai dengan pertimbangan yang lebih manusiawi. Dengan demikian, karyawan bisa dipertimbangkan untuk memperoleh haknya walaupun semua syarat tidak terpenuhi secara penuh. Untuk mempermudah perhitungan digunakan toolbox. Peningkatan insentif sangat penting dikelola dan dijalankan oleh perusahaan, maka Implementasi Metode Fuzzy Tsukamoto Pada Pertimbangan Peningkatan Insentif yang akan dilaksanakan pada perusahaan cabang PT. Pinus Merah Abadi bisa memberikan pandangan yang berbeda bagi perusahaan untuk mengambil keputusan mengenai promosi peningkatan karyawan ini. Aplikasi sistem penunjang keputusan mampu memberikan output terbaik dengan metode logika fuzzy yang berperan aktif menentukan hasil himpunan nilai masing-masing variabel[2]. Sistem dengan model fuzzy dapat memberikan alternatif dan mempercepat hasil dalam perhitungan output yang diinginkan[3]. Dalam banyak hal, logika fuzzy digunakan sebagai suatu cara untuk memetakan permasalahan dari input menuju output yang diharapkan ${ }^{[4]}$. Tujuan penelitian ini berupa analisis data yang ada mengenai peningkatan insentif karyawan tetap pada perusahaan cabang PT. Pinus Merah Abadi yang digunakan sebagai dasar untuk melakukan perhitungan berbasis teknologi informasi menggunakan metode fuzzy tsukamoto dalam peningkatan insentif karyawan. Sementara itu, manfaat dari dilakukakannya penelitian terhadap kasus ini yaitu perusahaan memiliki aplikasi untuk menghitung peningkatan insentif serta membantu karyawan dalam menghitung peningkatan insentif. Membuat karyawan bekerja mandiri dalam menghitung peningkatan insentif. Kontribusi lainnya sebagai bahan acuan bagi peneltian serupa selanjutnya dan sebagai bahan pertimbangan bagi manajemen perusahaan serupa untuk melakukan perhitungan yang sama. Agar pembahasan masalah pada kasus ini terfokus, maka penulis akan membatasinya sebagai berikut: Sistem informai yang akan dibuat nantinya hanya difokus kan untuk perhitungan peningkatan insentif, metode penelitian yang digunakan adalah metode Fuzzy Tsukamoto, pengujian perhitungan menggunakan toolbox matlab. Sementara itu perumusan masalah yang akan diteliti adalah Bagaimana sistem pendukung keputusan peningkatan insentif karyawan menggunakan metode fuzzy tsukamoto berbasis teknologi informasi?

\section{METODE PENELITIAN}

\subsection{Kerangka Kerja}

Pertimbangan Peningkatan Insentif Karyawan Perusahaan (Arridha Zikra Syah)| 987 
Adapun kerangka kerja penelitian yang dilaksanakan dapat dilihat dalam bagan dibawah ini :

a. Studi Pendahuluan

Pemahaman tentang teori dan konsep dengan mencari karya ilmiah ataupun buku yang berkaitan dengan sistem pendukung keputusan, peningkatan insentif dan pengangkatan karyawan tetap.

b. Pengumpulan Data

Kegiatan dalam mengumpulkan data dan informasi yang berkaitan dengan peningkatan insentif dan pengangkatan karyawan tetap.

c. Analisis Sistem

Melakukan analisa sistem yang akan dibuat berdasarkan permasalahan yang sedang diteliti.

d. Implementasi dan Pengujian Sistem

Sistem diimplementasikan menggunakan toolbox matlab untuk sistem pendukung keputusan berdasarkan permasalahan yang akan diteliti sekaligus menguji perhitungan fuzzy yang dilakukan.

\subsection{Teknik Pengumpulan Data}

a. Observasi, dilakukan di PT Pinus Merah Abadi untuk memperoleh gambaran sistem pendukung keputusan yang ada saat ini.

b. Wawancara, dilakukan untuk memperoleh analisis sistem pendukung keputusan sedang berjalan sesuai di PT Pinus Merah Abadi

c. Pengumpulan Dokumen, melalui analisis isi dan pengambilan basis data dari PT Pinus Merah Abadi

\section{Hasil dan Pembahasan}

\subsection{Analisis Sistem Pendukung Keputusan}

Dari analisis sistem pengambilan keputusan tersebut terlihat bahwa proses kalkulasi dilakukan semua masih secara manual. Selain itu, perhitungan mengenai sistem masih menggunakan kalkulasi yang sangat kaku.

\subsection{Analisa data}

\section{a. Data Kriteria}

Secara rinci, kriterian dan masing himpunan dalam kriteria tersebut dijabarkan sebagai berikut:

1) Sales Value (SV)

Merupakan penilaian yang dilakukan berdasarkan pencapaian target penjualan bulan yang bersangkutan

2) Sales Value (SV) - NPL

Merupakan penilaian yang dilakukan berdasarkan pencapaian marketing produk baru launching

3) Effective Performance (EP)

Merupakan penilaian yang dilakukan berdasarkan pemerataan target di setiap rute yang dilewati.

4) Item Per Transaksi (IPT)

Merupakan penilaian yang dilakukan berdasarkan keberagaman atau Bnya item yang tertera di setiap faktur penjualan dalam satu bulan.

5) ROA SKU NPL KSNI

Merupakan penilaian yang dilakukan berdasarkan Bnya produk baru yang bisa dipasarkan. 
b. Data alternatif

Alternatif dari sistem pendukung keputusan karyawan terdiri dari salesman dan spv. Hanya saja perolehan awal tergantung kepada perolehan salesmen maka sistem ini difokuskan kepada perhitungan peningkatan insetif salesmen.

Di PT. Pinus Merah Abadi saat ini terdapat dua puluh dua karyawan dengan jabatan salesmen. Dari hasil kalkulasi sementara, ditunjukan bahwa terdapat 108 peluang dalam memperoleh tingkatan insentif bagi salesmen. Tingkat paling rendah adalah tidak memperoleh pengingkatan sama sekali. Dan yang paling baik adalah memperoleh peningkatan maksimal.

\subsection{Variabel dan Himpunan Keanggotaan}

a. Sales Value (SV)

Fungsi keanggotaan Sales Value (SV) digambarkan melalui grafik linear pada gambar berikut:

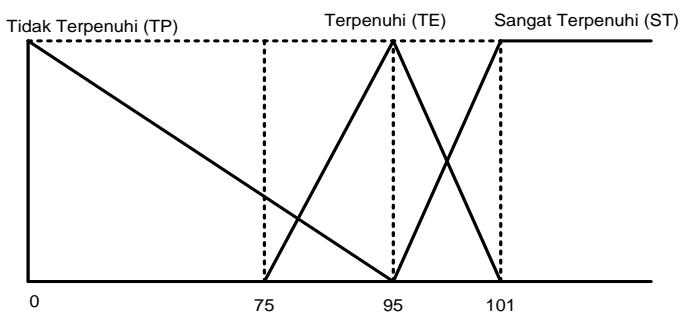

Gambar 1. Himpunan Keanggotaan Sales Value (SV)

b. Sales Value (SV) - NPL

Seperti halnya Sales Value, Fungsi keanggotaan Sales Value (SV) - digambarkan melalui grafik linear pada gambar berikut:

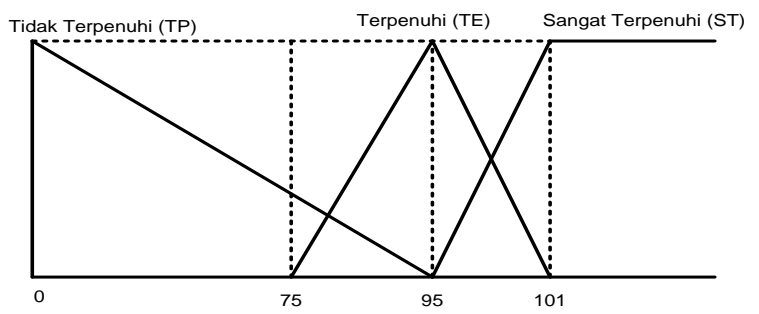

Gambar 2. Himpunan Keanggotaan Sales Value (SV)-NPL

\subsection{Effective Performance (EP)}

Variabel Effective Performance (EP) tiga himpunan keanggotaan. Fungsi keanggotaan Variabel Effective Performance (EP) digambarkan melalui grafik linear pada gambar berikut:

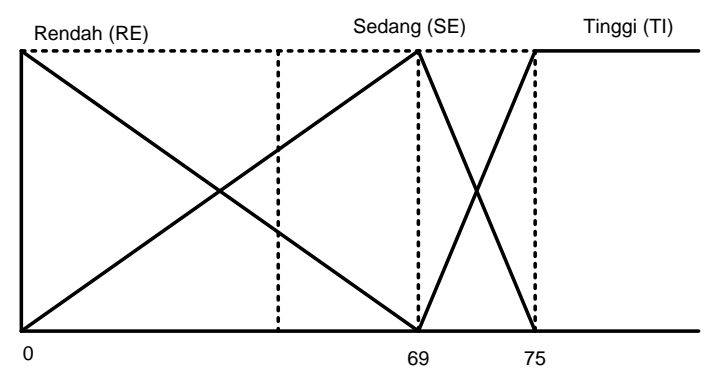

Gambar 3. Himpuanan KeanggotaanVariabel Effective Performance (EP)

Pertimbangan Peningkatan Insentif Karyawan Perusahaan (Arridha Zikra Syah) | 989 


\subsection{Item Per Transaksi (IPT)}

Variabel Item Per Transaksi (IPT) memiliki dua himpunan keanggotaan. Fungsi keanggotaan Variabel Item Per Transaksi (IPT) digambarkan melalui grafik linear pada gambar berikut:

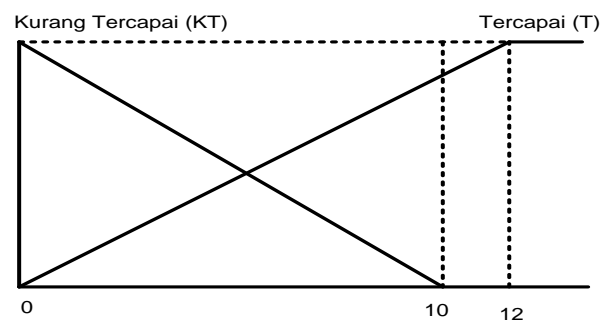

Gambar 4. Himpunan Keanggotaan Variabel Item Per Transaksi (IPT)

\subsection{ROA SKU NPL KSNI (ROA)}

ROA SKU NPL KSNI memiliki dua himpunan keanggotaan. Fungsi keanggotaan Variabel ROA SKU NPL KSNI digambarkan melalui grafik linear pada gambar berikut:

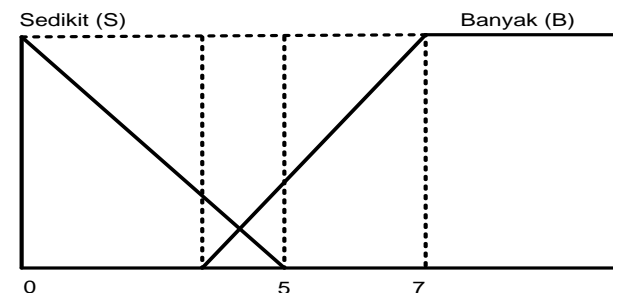

Gambar 5. himpunan keanggotaan ROA SKU NPL KSNI

\subsection{Peningkatan Insentif (PI)}

Peningkatan Insentif memiliki Tiga Himpunan Keanggotaan. Peningkatan iNsentif merupakan variabel output. Fungsi keanggotaan Variabel peningkatan insentif terdiri dari Rendah, Sedang dan Tinggi. Grafik Keanggotaan Fungsi Peningkatan insentif digambarkan melalui grafik linear pada gambar berikut:

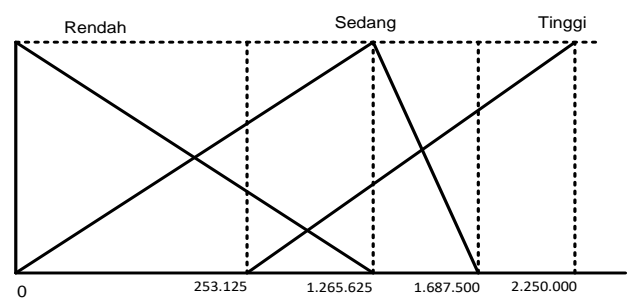

Gambar 6. fungsi keanggotaan peningkatan insentif

\subsection{Ruled Based}

Berdasarkan data yang diperoleh dan jumlah himpunan setiap variabel output. Sistem pendukung Keputusan Peningkatan Karyawan ini terdiri dari 107 aturan (Ruled Based). Operator yang digunakan untuk menghubungkan masing-masing kondisi input adalah or. Hal tersebut membuat perolehan output setara dengan fakta yang terdapat pada PT. Pinus Merah Abadi. Aturan tersebut dapat dilihat pada tabel berikut: 
Tabel 1. Ruled Based

\begin{tabular}{|c|c|c|c|c|c|c|c|c|c|c|c|c|c|}
\hline Rule ke & ROA & IPT & SV & $\begin{array}{l}\text { SV- } \\
\text { NPL }\end{array}$ & EP & PI & Rule ke & ROA & IPT & SV & $\begin{array}{l}\text { SV- } \\
\text { NPL }\end{array}$ & EP & PI \\
\hline RULE: 1 & B & $\mathrm{T}$ & ST & ST & $\mathrm{TI}$ & TI & ULE: 55 & $\mathrm{~S}$ & $\mathrm{~T}$ & ST & ST & $\mathrm{TI}$ & $\mathrm{TI}$ \\
\hline RULE: 2 & $\mathrm{~B}$ & $\mathrm{~T}$ & ST & ST & SE & TI & ULE: 56 & $\mathrm{~S}$ & $\mathrm{~T}$ & ST & ST & SE & $\mathrm{TI}$ \\
\hline RULE: 3 & B & $\mathrm{T}$ & ST & ST & $\mathrm{RE}$ & TI & ULE: 57 & $\mathrm{~S}$ & $\mathrm{~T}$ & ST & ST & $\mathrm{RE}$ & TI \\
\hline RULE: 4 & B & $\mathrm{T}$ & ST & TE & $\mathrm{TI}$ & TI & RULE: 58 & $\mathrm{~S}$ & $\mathrm{~T}$ & ST & TE & $\mathrm{TI}$ & $\mathrm{TI}$ \\
\hline RULE: 5 & B & $\mathrm{T}$ & ST & $\mathrm{TE}$ & SE & $\mathrm{TI}$ & RULE: 59 & $\mathrm{~S}$ & $\mathrm{~T}$ & ST & TE & SE & $\mathrm{TI}$ \\
\hline RULE: 6 & B & $\mathrm{T}$ & ST & TE & $\mathrm{RE}$ & TI & RULE: 60 & $\mathrm{~S}$ & $\mathrm{~T}$ & ST & $\mathrm{TE}$ & $\mathrm{RE}$ & SE \\
\hline RULE: 7 & B & $\mathrm{T}$ & ST & $\mathrm{TP}$ & TI & TI & RULE: 61 & $\mathrm{~S}$ & $\mathrm{~T}$ & ST & $\mathrm{TP}$ & $\mathrm{TI}$ & SE \\
\hline RULE: 8 & B & $\mathrm{T}$ & ST & TP & SE & SE & RULE: 62 & $\mathrm{~S}$ & $\mathrm{~T}$ & ST & TP & SE & SE \\
\hline RULE: 9 & B & $\mathrm{T}$ & ST & $\mathrm{TP}$ & $\mathrm{RE}$ & SE & RULE: 63 & $\mathrm{~S}$ & $\mathrm{~T}$ & ST & TP & $\mathrm{RE}$ & $\mathrm{RE}$ \\
\hline RULE: 10 & B & $\mathrm{T}$ & $\mathrm{TE}$ & ST & TI & $\mathrm{TI}$ & RULE: 64 & $\mathrm{~S}$ & $\mathrm{~T}$ & $\mathrm{TE}$ & ST & $\mathrm{TI}$ & $\mathrm{TI}$ \\
\hline RULE: 11 & $\mathrm{~B}$ & $\mathrm{~T}$ & TE & ST & SE & TI & JLE: 65 & $\mathrm{~S}$ & $\mathrm{~T}$ & TE & ST & SE & TI \\
\hline RULE: 12 & B & $\mathrm{T}$ & TE & ST & $\mathrm{RE}$ & TI & RULE: 66 & $\mathrm{~S}$ & $\mathrm{~T}$ & $\mathrm{TE}$ & ST & $\mathrm{RE}$ & SE \\
\hline RULE: 13 & B & $\mathrm{T}$ & TE & TE & $\mathrm{TI}$ & TI & ULE: 67 & $\mathrm{~S}$ & $\mathrm{~T}$ & TE & TE & $\mathrm{TI}$ & $\mathrm{TI}$ \\
\hline RULE: 14 & B & $\mathrm{T}$ & TE & TE & SE & $\mathrm{TI}$ & RULE: 68 & $\mathrm{~S}$ & $\mathrm{~T}$ & TE & $\mathrm{TE}$ & SE & $\mathrm{TI}$ \\
\hline RULE: 15 & B & $\mathrm{T}$ & $\mathrm{TE}$ & TE & $\mathrm{RE}$ & SE & RULE: 69 & $\mathrm{~S}$ & $\mathrm{~T}$ & $\mathrm{TE}$ & $\mathrm{TE}$ & $\mathrm{RE}$ & SE \\
\hline RULE: 16 & $\mathrm{~B}$ & $\mathrm{~T}$ & TE & $\mathrm{TP}$ & TI & SE & RULE: 70 & $\mathrm{~S}$ & $\mathrm{~T}$ & TE & TP & $\mathrm{TI}$ & SE \\
\hline RULE: 17 & B & $\mathrm{T}$ & $\mathrm{TE}$ & $\mathrm{TP}$ & SE & SE & RULE: 71 & $\mathrm{~S}$ & $\mathrm{~T}$ & $\mathrm{TE}$ & $\mathrm{TP}$ & SE & SE \\
\hline RULE: 18 & B & $\mathrm{T}$ & TE & $\mathrm{TP}$ & $\mathrm{RE}$ & $\mathrm{RE}$ & RULE: 72 & $\mathrm{~S}$ & $\mathrm{~T}$ & $\mathrm{TE}$ & TP & RE & $\mathrm{RE}$ \\
\hline RULE: 19 & B & $\mathrm{T}$ & TP & ST & TI & $\mathrm{TI}$ & 73 & $\mathrm{~S}$ & $\mathrm{~T}$ & TP & ST & $\mathrm{TI}$ & SE \\
\hline RULE: 20 & $\mathrm{~B}$ & $\mathrm{~T}$ & $\mathrm{TP}$ & ST & SE & SE & 74 & $\mathrm{~S}$ & $\mathrm{~T}$ & TP & ST & SE & SE \\
\hline RULE: 21 & B & $\mathrm{T}$ & TP & ST & $\mathrm{RE}$ & SE & 75 & $\mathrm{~S}$ & $\mathrm{~T}$ & TP & ST & $\mathrm{RE}$ & $\mathrm{RE}$ \\
\hline RULE: 22 & $\mathrm{~B}$ & $\mathrm{~T}$ & TP & TE & $\mathrm{TI}$ & SE & E: 76 & $\mathrm{~S}$ & $\mathrm{~T}$ & TP & TE & $\mathrm{TI}$ & SE \\
\hline RULE: 23 & B & $\mathrm{T}$ & $\mathrm{TP}$ & TE & SE & SE & ULE: 77 & $\mathrm{~S}$ & $\mathrm{~T}$ & TP & $\mathrm{TE}$ & SE & SE \\
\hline RULE: 24 & B & $\mathrm{T}$ & TP & TE & $\mathrm{RE}$ & $\mathrm{RE}$ & RULE: 78 & $\mathrm{~S}$ & $\mathrm{~T}$ & TP & $\mathrm{TE}$ & $\mathrm{RE}$ & $\mathrm{RE}$ \\
\hline RULE: 25 & B & $\mathrm{T}$ & TP & TP & $\mathrm{TI}$ & $\mathrm{RE}$ & RULE: 79 & $\mathrm{~S}$ & $\mathrm{~T}$ & TP & TP & $\mathrm{TI}$ & $\mathrm{RE}$ \\
\hline RULE: 26 & $\mathrm{~B}$ & $\mathrm{~T}$ & TP & $\mathrm{TP}$ & SE & $\mathrm{RE}$ & RULE: 80 & $\mathrm{~S}$ & $\mathrm{~T}$ & TP & TP & SE & $\mathrm{RE}$ \\
\hline RULE: 27 & B & $\mathrm{T}$ & TP & $\mathrm{TP}$ & $\mathrm{RE}$ & $\mathrm{RE}$ & RULE: 81 & $\mathrm{~S}$ & $\mathrm{~T}$ & TP & TP & $\mathrm{RE}$ & $\mathrm{RE}$ \\
\hline RULE: 28 & $\mathrm{~B}$ & KT & ST & ST & TI & TI & RULE: 82 & $\mathrm{~S}$ & KT & ST & ST & $\mathrm{TI}$ & $\mathrm{TI}$ \\
\hline RULE: 29 & $\mathrm{~B}$ & KT & ST & ST & SE & TI & 83 & $\mathrm{~S}$ & KT & ST & ST & SE & TI \\
\hline RULE: 30 & B & KT & ST & ST & $\mathrm{RE}$ & TI & 84 & $\mathrm{~S}$ & KT & ST & ST & $\mathrm{RE}$ & $\mathrm{TI}$ \\
\hline RULE: 31 & $\mathrm{~B}$ & KT & ST & TE & TI & TI & RULE: 85 & $S$ & KT & ST & TE & TI & TI \\
\hline RULE: 32 & B & KT & ST & TE & SE & TI & RULE: 86 & $\mathrm{~S}$ & KT & ST & TE & SE & TI \\
\hline RULE: 33 & B & KT & ST & TE & $\mathrm{RE}$ & TI & RULE: 87 & $\mathrm{~S}$ & KT & ST & TE & $\mathrm{RE}$ & SE \\
\hline RULE: 34 & $\mathrm{~B}$ & KT & ST & TP & $\mathrm{TI}$ & SE & RULE: 88 & $\mathrm{~S}$ & KT & ST & TP & $\mathrm{TI}$ & SE \\
\hline RULE: 35 & $\mathrm{~B}$ & KT & ST & $\mathrm{TP}$ & SE & SE & RULE: 89 & $\mathrm{~S}$ & KT & ST & TP & SE & SE \\
\hline RULE: 36 & B & KT & ST & $\mathrm{TP}$ & $\mathrm{RE}$ & SE & RULE: 90 & $\mathrm{~S}$ & KT & ST & TP & $\mathrm{RE}$ & $\mathrm{RE}$ \\
\hline RULE: 37 & B & KT & TE & ST & $\mathrm{TI}$ & TI & RULE: 91 & $\mathrm{~S}$ & KT & TE & ST & $\mathrm{TI}$ & $\mathrm{TI}$ \\
\hline RULE: 38 & B & KT & TE & ST & SE & $\mathrm{TI}$ & RULE: 92 & $\mathrm{~S}$ & KT & $\mathrm{TE}$ & ST & SE & $\mathrm{TI}$ \\
\hline RULE: 39 & B & KT & TE & ST & $\mathrm{RE}$ & TI & : 93 & $\mathrm{~S}$ & KT & $\mathrm{TE}$ & ST & $\mathrm{RE}$ & SE \\
\hline RULE: 40 & $\mathrm{~B}$ & KT & TE & TE & TI & TI & : 94 & $\mathrm{~S}$ & KT & TE & TE & $\mathrm{TI}$ & $\mathrm{TI}$ \\
\hline RULE: 41 & B & KT & TE & TE & SE & $\mathrm{TI}$ & RULE: 95 & $\mathrm{~S}$ & KT & $\mathrm{TE}$ & $\mathrm{TE}$ & SE & $\mathrm{TI}$ \\
\hline RULE: 42 & B & KT & TE & TE & $\mathrm{RE}$ & SE & RULE: 96 & $\mathrm{~S}$ & KT & TE & TE & $\mathrm{RE}$ & SE \\
\hline RULE: 43 & B & KT & $\mathrm{TE}$ & $\mathrm{TP}$ & TI & SE & RULE: 97 & $\mathrm{~S}$ & KT & $\mathrm{TE}$ & $\mathrm{TP}$ & $\mathrm{TI}$ & SE \\
\hline RULE: 44 & B & KT & TE & TP & SE & SE & RULE: 98 & $\mathrm{~S}$ & KT & TE & TP & SE & SE \\
\hline RULE: 45 & B & KT & $\mathrm{TE}$ & TP & $\mathrm{RE}$ & $\mathrm{RE}$ & RULE: 99 & $\mathrm{~S}$ & KT & $\mathrm{TE}$ & TP & $\mathrm{RE}$ & $\mathrm{RE}$ \\
\hline RULE: 46 & $\mathrm{~B}$ & KT & TP & ST & $\mathrm{TI}$ & SE & RULE: 100 & $S$ & KT & TP & ST & $\mathrm{TI}$ & SE \\
\hline RULE: 47 & B & KT & $\mathrm{TP}$ & ST & SE & SE & RULE: 101 & $\mathrm{~S}$ & KT & TP & ST & SE & SE \\
\hline RULE: 48 & B & KT & TP & ST & $\mathrm{RE}$ & SE & RULE: 102 & $S$ & KT & $\mathrm{TP}$ & ST & $\mathrm{RE}$ & $\mathrm{RE}$ \\
\hline RULE: 49 & $\mathrm{~B}$ & KT & TP & TE & TI & SE & RULE: 103 & $\mathrm{~S}$ & KT & TP & TE & $\mathrm{TI}$ & SE \\
\hline RULE: 50 & B & KT & TP & TE & SE & SE & RULE: 104 & $\mathrm{~J}$ & KT & $\mathrm{TP}$ & $\mathrm{TE}$ & SE & SL \\
\hline
\end{tabular}




\begin{tabular}{|l|l|l|l|l|l|l|l|l|l|l|l|l|l|}
\hline Rule ke & ROA & IPT & SV & $\begin{array}{l}\text { SV- } \\
\text { NPL }\end{array}$ & EP & PI & Rule ke & ROA & IPT & SV & $\begin{array}{l}\text { SV- } \\
\text { NPL }\end{array}$ & EP & PI \\
\hline RULE: 51 & B & KT & TP & TE & RE & RE & RULE: 105 & S & KT & TP & TE & RE & RE \\
\hline RULE: 52 & B & KT & TP & TP & TI & RE & RULE: 106 & S & KT & TP & TP & TI & RE \\
\hline RULE: 53 & B & KT & TP & TP & SE & RE & RULE: 107 & S & KT & TP & TP & SE & RE \\
\hline RULE: 54 & B & KT & TP & TP & RE & RE & & & & & & & \\
\hline
\end{tabular}

\subsection{Algoritma Fuzzy Tsukamoto}

Perhitungan dilakukan berdasarkan data yang diperoleh. Data yang dipakai untuk perhitungan adalah data namaSaudara Abdi Nurwanda, dengan perolehan SV=101,00, SVNPL=98,11, EP=75,79, IPT=12,37, ROA SKU NPL KSNI=5,00.

a. Fuzzifikasi

Perhitungan fuzzifikasi menggunakan fungsi linear. Nilai fuzzy masing-masing himpunan untuk variabel bersesuaian berasal dari data dimana SV=101,00, SVNPL=98,11, EP=75,79, IPT=12,37, ROA SKU NPL KSNI=5,00. Hasil Fuzzifikasi untuk masing-masing variabel dan himpunan keanggotaan bersesuaian dapat dilihat pada tabel berikut:

Tabel 2. Nilai Fuzzifikasi Masing-Masing Himpunan Untuk Input Bersesuaian

\begin{tabular}{|l|l|l|l|}
\hline Variabel & $\mathbf{X}$ & $\begin{array}{l}\text { Fungsi } \\
\text { Keanggotaan }\end{array}$ & Nilai $\boldsymbol{\mu}$ \\
\hline SV & TP & Linear Menurun & 0,00 \\
\hline SV & TE & Segitiga & 0,00 \\
\hline SV & ST & Linear Menaik & 1,00 \\
\hline SV-NPL & TP & Linear Menurun & 0,00 \\
\hline SV-NPL & TE & Segitiga & 0,38 \\
\hline SV-NPL & ST & Linear Menaik & 0,62 \\
\hline EP & RE & Linear Menurun & 0,00 \\
\hline EP & SE & Segitiga & 0,00 \\
\hline EP & TI & Linear Menaik & 1,00 \\
\hline IPT & KT & Linear Menurun & 0,00 \\
\hline IPT & T & Linear Menaik & 1,00 \\
\hline ROA & S & Linear Menurun & 0,00 \\
\hline ROA & B & Linear Menaik & 1,00 \\
\hline
\end{tabular}

b. Inferensi

Tabel 3. Hasil Inferensi

\begin{tabular}{|l|l|l|}
\hline Rules n & apredn & Z n \\
\hline Rule 1 & 0,00 & $253.125,00$ \\
\hline Rule 2 & 1,00 & $2.250 .000,00$ \\
\hline Rule 3 & 1,00 & $2.250 .000,00$ \\
\hline Rule 4 & 1,00 & $2.250 .000,00$ \\
\hline Rule 5 & 1,00 & $2.250 .000,00$ \\
\hline Rule 6 & 1,00 & $2.250 .000,00$ \\
\hline Rule 7 & 1,00 & $2.250 .000,00$ \\
\hline Rule 8 & 2,00 & $2.531 .250,00$ \\
\hline Rule 9 & 2,00 & $2.531 .250,00$ \\
\hline Rule 10 & 1,00 & $2.250 .000,00$ \\
\hline
\end{tabular}

c. Defuzifikasi

Defuzzifikasi nilai peningkatan insentif saat dimasukan kerumus adalah sebagai berikut: 


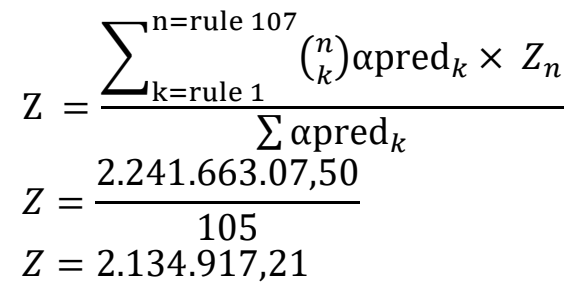

Berdasarkan perhitungan fuzzy tsukamoto pada peningkatan insentif karyawan PT. Pinus Merah Abadi untuk saudara abdi adalah Rp. 2. 134.917,21.

\section{KESIMPULAN}

Berdasarkan hasil analisis dapat diketahui bahwa:

a. Terdapat pengaruh insentif dengan semua capaian antara insentif terhadap kinerja pencapaian karyawan secara simultan.

b. Perolehan hasil perhitungan Fuzzy dengan metode Tsukamoto mendekati nilai perolehan dengan hitungan standar perusahaan hanya saya lebih besar, hal ini dikarenakan oleh beberapa input yang berada di atas standar pencapaian, sehingga data yang digunakan dasar untuk melakukan perhitungan berbasis teknologi informasi menggunakan metode fuzzy tsukamoto dalam peningkatan insentif karyawan sesuai dengan analisis yang dilakukan.

c. Besaran insentif bergantung pada ruled yang diberikan. Perbedaan pendapatan setiap kriteria pada setiap karyawan akan menyebabkan perbedaan pendapatan. Sehingga setiap pencapaian sangat berarti dan dihargai.

\section{DAFTAR PUSTAKA}

[1] Arifin, Z. "Pengaruh Isentif Terhadap Kinerja PT Idec Wood di Tarakan", eJournal Administrasi Bisnis, vol. 5 (4), pp. 1292-1303, 2017.

[2] Rizaldi, R., \& Yuma, F. M.," ANALISIS PEMILIHAN KARYAWAN TELADAN MENGGUNAKAN METODE FUZZY TSUKAMOTO PADA PT. HARIAN HALUAN SUMBAR MANDIRI", In Seminar Nasional Royal (SENAR), Vol. 1, No. 1, pp. 321-326, September 2018.

[3] Aswati, S., Mulyani, N., Siagian, Y., \& Syah, A. Z. (2015). Sistem Pendukung Keputusan Penerima Beasiswa Pendidikan Yayasan (Studi Kasus STMIK Royal) dengan Metode Simple Additive Weight. SESINDO 2015, 2015.

[4] Anggraeni, D., "SISTEM PENUNJANG KEPUTUSAN PENERIMAAN SISWA BARU DENGAN MENGGUNAKAN METODE LOGIKA FUZZY PADA SEKOLAH MENENGAH TINGKAT ATAS (SMA) NEGERI 1 TANJUNG RAYA AGAM", JURTEKSI ROYAL, Vol 3 No 1, pp. 1-10, Desember 2016.

[5]A. Wanto, "Analisis Penerapan Fuzzy Inference System (FIS) Dengan Metode Mamdani Pada Sistem Prediksi Mahasiswa Non Aktif (Studi Kasus : AMIK Tunas Bangsa Pematangsiantar)," in Seminar Nasional Inovasi Dan Teknologi Informasi (SNITI) 3, 2016, vol. 3, pp. 393-400. 